\title{
Mutant K-ras oncogene regulates steroidogenesis of normal human adrenocortical cells by the RAF-MEK-MAPK pathway
}

\section{C-H Wu', Y-F Chen', J-Y Wang ${ }^{3}$, M-C Hsieh", C-S Yeh, , S-T Lian², S-J Shin ${ }^{4}$ and S-R Lin",2}

'Graduate Institute of Medicine, Kaohsiung Medical University Kaohsiung, 80317, Taiwan; ${ }^{2}$ Department of Laboratory Medicine, Kaohsiung Medical University Kaohsiung, 80317, Taiwan; ${ }^{3}$ Graduate Institute of Biochemistry, Kaohsiung Medical University Kaohsiung, 8031 7, Taiwan; ${ }^{4}$ Internal Medicine, Kaohsiung Medical University Kaohsiung, 80317, Taiwan

The result of our previous study has shown that the K-ras mutant ( $p$ K568MRSV) transfected human adrenocortical cells can significantly increase cortisol production and independently cause cell transformation. The aim of this study is to investigate the effect of the active K-ras oncogene on the cortisol production in normal human adrenocortical cells. First we used isopropyl thiogalactoside to induce the inducible mutant K-ras expression plasmid, pK568MRSV, in the stable transfected human adrenocortical cells. The result showed that the increase of RasGTP levels in transfected cells was time-dependent after isopropyl thiogalactoside induction. Additionally, results from Western blot analysis revealed significant elevation in phosphorylation of c-Raf-I and Mitogen-activated protein kinase. We also detected the levels of mRNA encoding Cholesterol

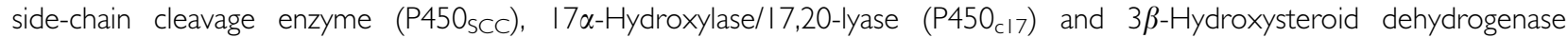
$(3 \beta \mathrm{HSD})$ were increased in human adrenocortical cells transfected with mutant K-ras after IPTG treatment. The increase of mRNA amount in $\mathrm{P}_{450_{\text {scc }}} \mathrm{P} 450_{\mathrm{cl}}$ and $3 \beta \mathrm{HSD}$ and the elevation of cortisol level were inhibited with a pretreatment of PD098059, a specific extracellular signal-regulated kinase inhibitor. In our previous report, we proved that lovastatin, a pharmacological inhibitor of $\mathrm{p} \mathrm{I}^{\text {ras }}$ function, also reversed the increase of cortisol level in mutant K-ras stably transfected human adrenocortical cells. Taken together, these findings proved that the active mutant Ras enhanced not only cell proliferation but also steroidogenesis in steroidogenic phenotype cells by activating Raf-MEK-MAPK related signal transduction pathway. Therefore, we believe that K-ras mutants influence regulation of steroidogenesis in adrenocortical cells through RAFMEK-MAPK pathway.

British Journal of Cancer (2002) 87, 1000 - 1005. doi:I0.1038/sj.bjc.6600589 www.bjcancer.com

(c) 2002 Cancer Research UK

Keywords: K-ras mutants; functional adrenal tumour; normal adrenocortical cells; cortisol secretion; RAF; MEK

Our laboratory has been studying human functional adrenocortical tumours since 1993 (Lin et al, 1994, 1996, 1998a,b, 2000; Shu et al, 2001; Wu et al, 2002). We have found that the K-ras gene enhanced the efficiency of cell proliferation and elevation of cortisol production in bovine adrenocortical cells. However, it did not independently induce cell transformation (Shu et al, 2001). To increase the credibility of our experiments, we cultured normal human adrenocortical cells from donors for mutant K-ras gene analysis. The cultured normal human adrenocortical cells synthesised and secreted steroid hormones. The levels of cortisol and aldosterone indicated that the cultured cells were mainly fasciculata reticularis cells with very few contaminating glomerulosa cells $(\mathrm{Wu}$ et al, 2002). The results also showed that cortisol levels of the K-ras mutant ( $p K 568 M R S V)$ transfected human adrenocortical cells were 18 to 25 times higher than that in controls. In addition, the mutant $\mathrm{K}$-ras gene could induce morphologic alterations in the transfected adrenocortical cells (Wu et al, 2002). These studies proved that the mutant K-ras gene takes part in steroidogenesis of human functional adrenocortical cells. Nevertheless, it is not quiet clear

*Correspondence: S-R Lin, Department of Clinical Pathology, Kaohsiung Medical University, No 100, Shih-Chuan Ist Road, Kaohsiung, 80317, Taiwan; E-mail: srlin@ms2.hinet.net

Received 27 June 2002; accepted 14 August 2002 whether the mutant K-ras gene enhances steroidogenesis through Mitogen-activated protein kinase (MAP kinase, MAPK) pathway or others.

The core components of the MAPK signalling cascades are three sequential kinases, including MAP kinase (MAPK, or extracellular signal-regulated kinase, ERK), MAPK kinase (MAPKK, or MAPK/ERK kinase, MEK), and MAPKK kinase (MAPKKK, or MEK kinase, MEKK). There are three characterised MAPK signalling pathways: (1) the Ras-to-MAPK signal transduction pathway (or ERK pathway), which is responsive to signals from receptor tyrosine kinase and some heterotrimeric G-protein-coupled receptors, which promote cell proliferation or differentiation. Ras acts as a molecular switch by cycling between active GTP-bound and inactive GDP-bound states. The active RasGTP form transfers the signal to Raf. The active Raf will phosphorylate MEK and then the phosphorylated MEK will phosphorylate ERK1/2(MAPK). Consequently, the phosphorylated ERK1/2 will activate a series of target proteins such as the ribosomal protein S6 kinases (RSKs), E1k-1, SOS, STATS, and C-Myc, which lead to consequent reactions (Treisman, 1996; Fanger et al, 1997; Elion, 1998); (2) the stress-activated protein kinase/c-Jun N-terminal kinase (SAPK/ JNK) pathway; and (3) the p38 pathway (Robinson and Cobb, 1997; Garrington and Johnson, 1999). Many inhibitors are used to stop signal transduction in Ras/MAPK pathway research. One of them, PD098059, a synthetic inhibitor of MEK (MAPKK) has 
high specificity and has been used by other researchers. Some studies have indicated that PD098059 failed to inhibit the stress, the stimulated JNK/SAPK and the p38 pathways, demonstrating its specificity for the ERK pathway (Alessi et al, 1995; Dudley et al, 1995).

Interestingly, most patients with functional adrenocortical tumours sought hospital treatment not owing to the pain caused by the cancer but owing to the physiological imbalance caused by excess secretion of cortisol. Therefore, the influence of hormone secretion seems to be more significant than that of cell growth regulation in adrenocortical tumours. In the past, research regarding cholesteroid regulation has often focused on the well known regulation of elevated caused by adrenocorticotropic hormone (ACTH) and Angiotensin II (Fredlund et al, 1975; Roskelley and Auersperg, 1995; Toaff et al, 1979). Little is known concerning the association hormone secretion of oncogenes with secretion regulation. Based on our previous results, we assumed that the active K-ras oncogene induced sterogenesis in adrenocortical cells through Ras-to-MAPK pathway. To prove our assumption, we used the mutant K-ras to activate the RAF/MEK (extracellular signal-related kinase kinase)/MAPK/ERK pathway. In order to understand whether mutant K-Ras activated C-Raf and MAP kinase, we transfected the $p K 568 M R S V$, the inducible mutant $\mathrm{K}$ ras oncogene expression plasmid, into normal human adrenocortical cells (Wu et al, 2002). Then we analysed the level of RasGTP during the extension time after IPTG treatment and the level of phosphorylated c-Raf-1 and MAP kinase by Western blot. We used a specific MAPK kinase (MEK) inhibitor, PD098050, to inhibit signal transduction to observe whether mutant K-ras induced on increase of mRNA levels of Cholesterol side-chain cleavage enzyme (P450 SCC $\left._{\text {C }}\right), 17 \alpha$-Hydroxylase/17, 20-lyase $\left(\mathrm{P}^{4} 0_{\mathrm{c} 17}\right)$ and $3 \beta$-Hydroxysteroid dehydrogenase $(3 \beta \mathrm{HSD})$ and the cortisol levels in transfected cells. By doing this, we hope the mechanism of the $\mathrm{K}$-ras oncogene taking part in steroidogenesis will be further understood.

\section{MATERIALS AND METHODS}

\section{Mutant K-ras gene stably transfected human adrenocortical} cell culture

The cultured normal human adrenocortical cells synthesised and secreted steroid hormones. The levels of cortisol and aldosterone secretion indicated that the cultured cells were mainly fasciculata reticularis cells with very few contaminating glomerulosa cells as described previously (Wu et al, 2002). Cells $\left(2 \times 10^{5}\right)$ in a 35$\mathrm{mm}$ plate were transfected with pOPRSV (control vector) and pK568MRSV K-ras expression plasmids by CLONfectin method (BD Biosciences Clontech, Palo Alto, CA, USA). Cells to be transfected were removed from the cultures and the CLONfectin/DNA media solution was gently applied. The plates were incubated at $37^{\circ} \mathrm{C}$ for $1-4 \mathrm{~h}$ in a $\mathrm{CO}_{2}$ incubator. CLONfectin/DNA- media solution was removed and then cells were washed with medium or $1 \times$ phosphate buffer saline (PBS). Fresh complete growth medium was added and the plates were incubating for another $48 \mathrm{~h}$. Then the growth medium was changed to the medium containing $400 \mu \mathrm{g} \mathrm{ml}^{-1} \mathrm{G} 418$ (BD Biosciences Clontech) and changed every 2 to 3 days to select the cell monoclone containing expression plasmid.

\section{Construction of GST-RBD of Raf-1 expression plasmid}

Using the PCR we constructed the expression plasmid for minimal Ras-binding domain of human Raf-1 (aa 51-131) from the human liver Marathon-ready cDNA (BD Biosciences Clontech, CA, USA). The oligonucleotides used to amplify a fragment of human c-raf-1 were $5^{\prime}$-CACAGATGGATCCAAGACAAGCAACAC-3' and 5'-GGG-
AAGAAT-TCACAGGAAATCTAC-3' (Herrmann et al, 1995) cDNA. The resulting 412-base pair fragment was cleaved with $B a m \mathrm{HI}$ and EcoRI, purified, and cloned into the GST fusion vector pGEX-4T-2 (Amersham, Pharmacia Biotech UK, Ltd) as described previously (Lin et al, 2000). The resulting plasmid, pGEX-RBD, was transformed into E. coli strain TG1. The correct orientation of the RBD of Raf-1 cDNA was confirmed by sequencing.

\section{Expression and purification of GST-RBD of Raf-1 fusion protein}

The expression of fusion protein was performed basically as described by Guan and Dixon (1991). Twenty millilitres of an overnight culture was inoculated into $1 \mathrm{l}$ of 2 XYT ( $10 \mathrm{~g}$ yeast extract, $16 \mathrm{~g}$ tryptone and $5 \mathrm{~g}$ sodium chloride $(\mathrm{NaCl})$ in $1 \mathrm{l}$ ) containing $50 \mu \mathrm{g} \mathrm{ml}^{-1}$ ampicillin. The culture was incubated vigorously at $37^{\circ} \mathrm{C}$ until an absorption of one at $600 \mathrm{~nm}$ was reached. IPTG was then added and cells were harvested by centrifugation and suspended in $10 \mathrm{ml}$ PBST $(2 \mathrm{mM}$ EDTA, $0.1 \% \beta$ mercaptoethanol, $0.2 \mathrm{mM}$ PMSF and $5 \mathrm{mM}$ benzamidine) after $3 \mathrm{~h}$ incubation. Bacterial lysate was centrifuged at $4{ }^{\circ} \mathrm{C}$ to remove the insoluble fraction. One millilitre of the bacterial supernatant containing soluble proteins was mixed with $2 \mathrm{ml} 50 \%\left(\mathrm{v} \mathrm{v}^{-1}\right)$ glutathione agarose beads and incubated $30 \mathrm{~min}$ at $4^{\circ} \mathrm{C}$ with gentle shaking. The agarose beads were washed four times with $10 \mathrm{ml}$ PBST. The fusion protein was eluted by competition with glutathione using $2 \times 2 \mathrm{~min}$ washes with $1 \mathrm{ml}$ of $50 \mathrm{~mm}$ Tris (pH 8.0) containing $10 \mathrm{~mm}$ glutathione. Free glutathione was removed by dialysis against $50 \mathrm{~mm}$ Tris $(\mathrm{pH} 8.0), 150 \mathrm{mM} \mathrm{NaCl}$, $0.1 \% \beta$-mercaptoethanol. The purified GST-RBD of Raf- 1 protein was recovered.

\section{Precipitation and immunoblot of active form RasGTP by GST-RBD of Raf-1 fusion protein}

The desired amount of crude GST-RBD of Raf-1 fusion protein was incubated with glutathion-agarose beads at room temperature for $30 \mathrm{~min}$. The beads were isolated by centrifugation and washed three times with RIPA buffer. Mutant K-ras gene stably transfected human adrenocortical cells were grown in Ham's F-12 medium containing $10 \%$ foetal calf serum with $2.5 \mathrm{mM}$ IPTG, and cells from a $9 \mathrm{~cm}$ dish were lysed and scraped in $1 \mathrm{ml}$ of RIPA buffer containing $50 \mathrm{~mm}$ Tris $\mathrm{pH} 8.0,150 \mathrm{mM} \mathrm{NaCl}, 0.5 \%$ doc, $1 \%$ NP40, $0.1 \%$ SDS, $0.1 \mu \mathrm{M}$ aprotinin, $1 \mu \mathrm{M}$ leupeptin and $1 \mathrm{mM}$ PMSF at $4^{\circ} \mathrm{C}$. Lysates were centrifuged at 14000 r.p.m for $8 \mathrm{~min}$ in an eppendorf centrifuge to remove nuclei. GST-RBD, precoupled to glutathion-agarose-beads in RIPA buffer, was added and the lysates were incubated at $4^{\circ} \mathrm{C}$ for $30 \mathrm{~min}$. Beads were collected by centrifugation, washed three times with RIPA buffer and resuspended in sample buffer (10\% glycerol, $60 \mathrm{~mm}$ Tris, pH 6.8. $2 \%$ SDS. $300 \mathrm{~mm} \quad \beta$-mercaptoethanol). The protein samples were separated on vertical slab gels composed of $10 \%$ polyacrylamide containing $0.1 \%$ sodium dodecyl sulphate (SDS) prepared in $3 \mathrm{~mm}$ Tris- $\mathrm{HCl}, \mathrm{pH} 8.8$, as described previously (Lin et al, 2000). Following electrophoresis, the protein was electroblotted to a nitrocellulose membrane (Schleicher \& Schusll $\mathrm{GmbH}$, Dassel, Germany). The membrane fixed with protein was incubated with mouse monoclonal antibodies (mAbs) specific for the K-ras p 21 product $\left(25 \mathrm{mg} \mathrm{ml}^{-1}\right.$ ) (Santa Cruz Biotechnology, Inc.), and the excess unbounded antibodies were then washed off. The membrane binding with the mouse mAbs was incubated with a solution of secondary goat anti-mouse IgG conjugated with alkaline phosphatase $(1: 3000$, Bio-Rad, Hercules, CA, USA) The Ras protein was detected by enhanced chemiluminescence (ECL) detection system (Amersham Pharmacia Biotech UK, Ltd). Blot was then exposed to Kodak XAR film (Eastman Kodak, Rochester, NY, USA). 


\section{Western blot}

The protein extracts, obtained from mutant K-ras gene stably transfected human adrenocortical cell, were purified and electrophoresed through vertical slab gels as described above. Briefly, following electrophoresis, the proteins were transferred to a nitro-cellulose membrane by an electrophoretic gel transfer device. The membrane fixed with proteins was incubated with mouse monoclonal antibodies specific for the c-Raf-1, phosphorylated raf-1 (p-raf-1), MAPK, phosphorylated MAPK (p-ERK, E-4) (Santa Cruz Biotechnology Inc., Santa Cruz, CA, USA), respectively. The membrane binding with the mouse mAbs was incubated with a solution of secondary goat anti-mouse IgG conjugated with alkaline phosphotase $(1: 3000$, Bio-Rad, Hercules, CA, USA) The target proteins were detected by enhanced chemiluminescence (ECL) detection system (Amersham. Pharmacia Biotech UK Ltd). Blot was then exposed to Kodak XAR film (Eastman Kodak, Rochester, NY, USA).

\section{PD098059 MAPK Kinase inhibitor treatment}

The $p$ K568MRSV transfected adrenocortical cells were treated with $10 \mathrm{mM}$ PD098059 for $45 \mathrm{~min}$ and then $2.5 \mathrm{~mm}$ IPTG was added. The mixture was incubated for $36 \mathrm{~h}$. The PD098059/IPTG-treated cells were then ready for cortisol level detection and MAPK kinase assay. The PD098059/IPTG-treated cell lysates and control cell lysates were immunoprecipitated with anti-ERK monoclonal antibody (Santa Cruz Biotechnology Inc., Santa Cruz, CA, USA). The immunocomplexes were then ready for MAP kinase assay.

\section{MAP kinase assay}

Proteins were obtained from $\mathrm{K}$-ras expression plasmids transfected cells and control cells. Supernatant $(0.5 \mathrm{ml})$ containing $0.5 \mathrm{mg}$ protein was incubated with $10 \mu \mathrm{l}$ of goat anti-ERK antibodies (Santa Cruz Biotechnology Inc., Santa Cruz, CA, USA) for $2 \mathrm{~h}$ at $4{ }^{\circ} \mathrm{C}$. The immunocomplexes were precipitated by centrifugation and washed two times with buffers A, B $(500 \mathrm{mM} \mathrm{LiCl}, 100 \mathrm{~mm}$ Tris, $1 \mathrm{mM}$ DTT, $0.1 \%$ Triton X-100; $\mathrm{pH} 7.6)$, and C (20 mM MOPS, 2 mM EGTA, $10 \mathrm{~mm} \mathrm{MgCl}_{2}, 1 \mathrm{~mm}$ DTT, $0.1 \%$ Triton X$100 ; \mathrm{pH}$ 7.2), respectively ERK activities in the immunocomplexes were measured (Alessi et al, 1995). Immunocomplexes were incubated with $35 \mu \mathrm{l}$ of buffer $\mathrm{C}$ supplemented with myelin basic protein (MBP; $6 \mu \mathrm{g}$; Upstate Biotechnology), $\left[\gamma_{-}{ }^{32} \mathrm{P}\right]$ ATP $(5 \mu \mathrm{Ci})$, and $\mathrm{MgCl}_{2}(50 \mathrm{mM})$ for $20 \mathrm{~min}$ at $37^{\circ} \mathrm{C}$ with vortexing every $5 \mathrm{~min}$. To stop the reaction, $15 \mu \mathrm{l}$ of $4 \times$ Laemmli buffer was added, and the mixture was boiled for $5 \mathrm{~min}$. Proteins in the kinase reaction were resolved by SDS-PAGE (15\% gel) and subjected to autoradiography.

\section{Northern blot}

Total RNA was extracted with acid-guanidium phenol/chloroform assay (AGPC) from transfected cells. Twenty micrograms of total RNA was denatured with $6.5 \%$ formaldehyde and $50 \%$ formaldehyde for $15 \mathrm{~min}$ at $55^{\circ} \mathrm{C}$ and separated by electrophoresis on $1.2 \%$ agarose gels containing $1.1 \%$ formaldehyde. Then RNA was transferred to nylon membrane (Schleicher and Schuell GmbH, Dassel, Germany) and fixed. The blots were successively hybridised with human $\mathrm{P} 450_{\mathrm{SCC}} \mathrm{cDNA}$, human $\mathrm{P} 40_{\mathrm{C} 17} \mathrm{cDNA}, 3 \beta \mathrm{HSD} \mathrm{cDNA}$ and human $\beta$-actin cDNA. The hybridised filters were then washed twice with washing buffer (Solution I: $3 \times$ SSC, $0.5 \%$ SDS; Solution II: $0.5 \times \mathrm{SSC}, 0.1 \% \mathrm{SDS}$ ) at $65^{\circ} \mathrm{C}$ to wash off the unbounded probe. The membrane was exposed to Kodak X-film at $-70^{\circ} \mathrm{C}$ for autoradiography. $\beta$-actin signal was used to normalise data for the above mRNA. All of the probes were confirmed by direct sequencing.

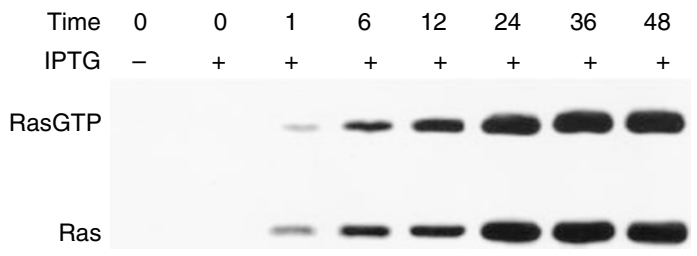

Figure I Time course of RasGTP formation after treatment with IPTG. The normal human adrenocortical cells transfected with pK568MRSV plasmid were induced with $2.5 \mathrm{mM}$ IPTG. Then the active RasGTP form was precipitated by GST-RBD of Raf-I fusion protein and immunoblotted as described in Materials and Methods. The RasGTP levels were detected at $0,1,6,12,24,36$ and $48 \mathrm{~h}$ after IPTG induction. Upper panels show the amount of RasGTP; lower panels show total amount of Ras in 10\% of the extract. The amount of RasGTP was increased with the elongation of IPTG induction. Plus (+) indicates when present; minus $(-)$ indicates when absent.

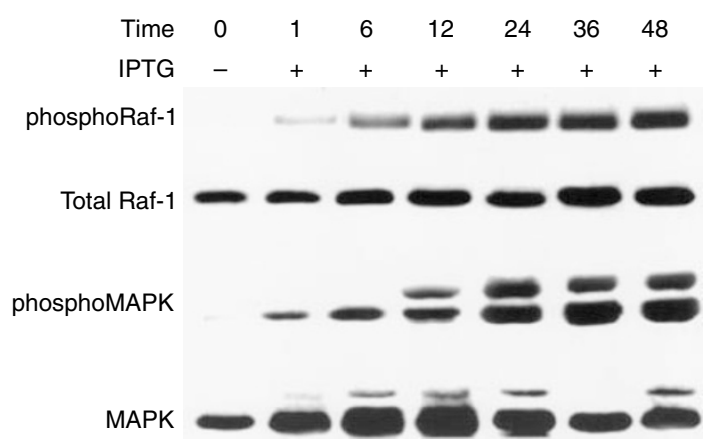

Figure 2 Time course of the phosphorylation of c-Rafl and MAPK in pK568MRSV transfected adrenocortical cells after treatment with IPTG. Crude protein extract from transfected cells was electrophoresised and transfered to PVDF as described in Materials and Methods. And then, it was immunobloted with monoclonal antibodies specific to phosphorylated c-Rafl (p-Raf-I), phosphorylated MAPK and control c-Raf-I and MAPK, respectively. The amounts of phosphorylated c-Raf-I ( $p-R a f-I$ ) and phosphorylated MAPK; and control MAPK and c-Raf-I were detected at 0,1 , $6,12,24,36$ and $48 \mathrm{~h}$ after IPTG induction. The amounts of phosphorylated c-Raf-I and MAPK were increased with the elongation of IPTG treatment. Plus $(+)$ indicates when present; minus $(-)$ indicates when absent.

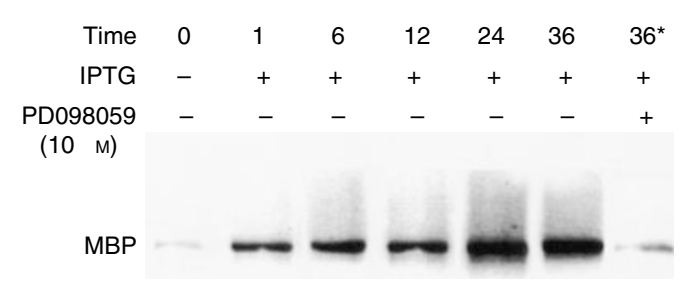

Figure 3 The effect of PD098059 pretreatment and the time course of MEK activity in PK568MRSV transfected adrenocortical cells after treatment with IPTG. Kinase activity was measured using myelin basic protein (MBP) as a substrate as described in Materials and Methods and significantly increased at 6, 12, 24 and $36 \mathrm{~h}$ after IPTG induction. *The 36* lane represented the pK568MRSV transfected cells treated with $10 \mu \mathrm{M}$ PD098059 for $45 \mathrm{~min}$ before the addition of $2.5 \mathrm{mM}$ IPTG and then incubation for $36 \mathrm{~h}$ in the presence of PD098059 and IPTG. With pretreatment of PD098059, the MEK activity was obviously inhibited in pK568MRSV transfected adrenocortical cells after treatment with IPTG. Plus $(+)$ indicates when present; minus $(-)$ indicates when absent. 
A
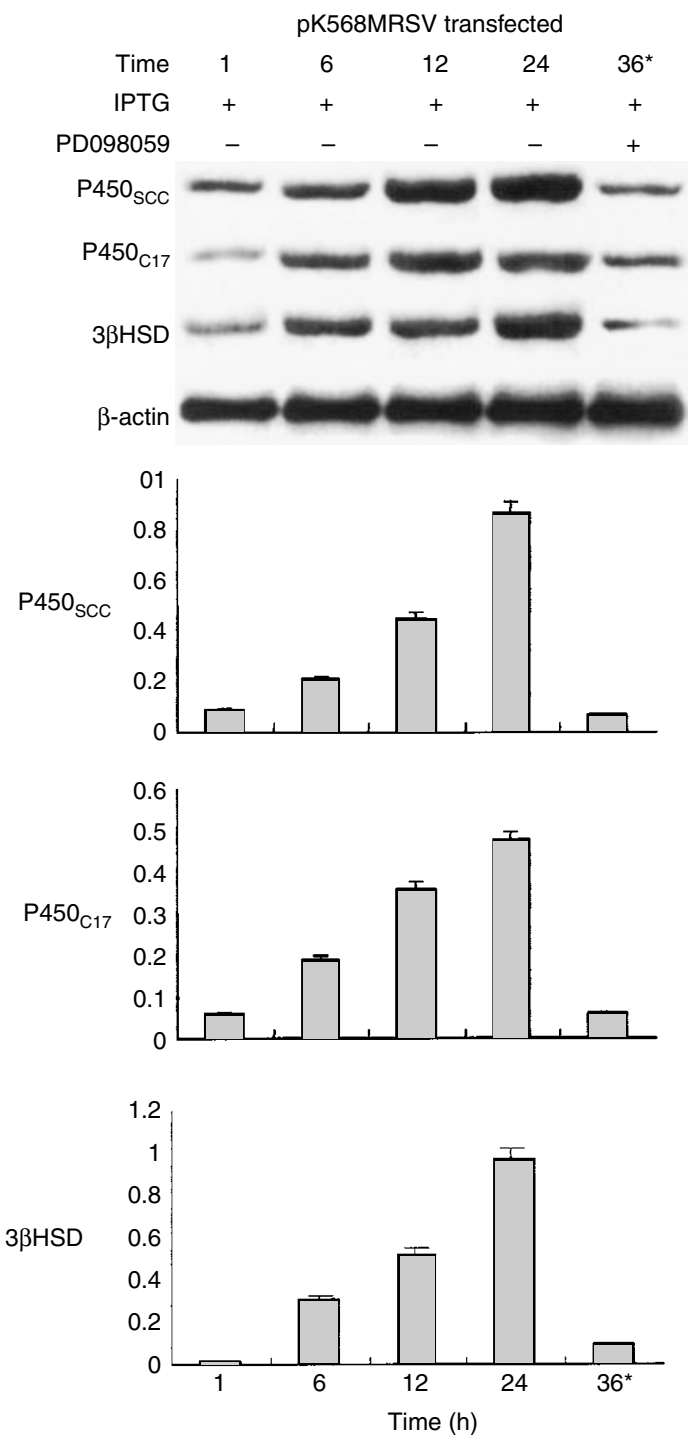

B

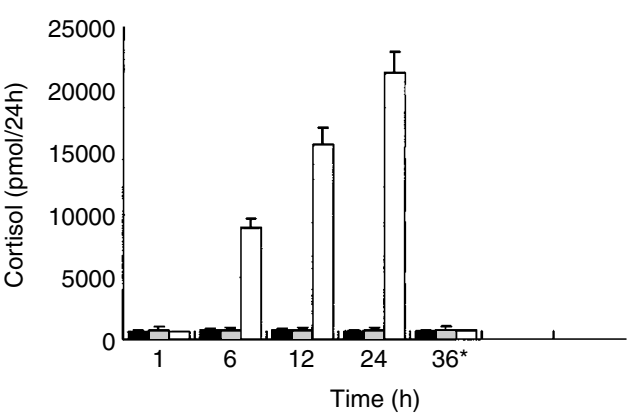

Figure 4 Effect of PD098059 on cortisol production or P450scc,

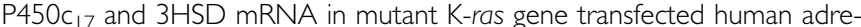
nocortical cells. pK568MRSV or pOPRSVI transfected adrenocortical cells were treated with IPTG for 1, 6, 12, 24 and $36 \mathrm{~h}$. Then the total RNA was extracted from the treated cells for Northern blot analysis. The histogram revealed the densitometry data of Northern blot of p450scc, p450 17 and 3HSD at every time point. The data indicates that their mRNA levels increased with incubation time, however, the increase was blocked by PD69859 as shown in lane 36*. Cortisol level in culture medium was detected by EIA and was found to increase with the elongation of

\section{Cortisol level detection}

The cell clones containing stable expression vector DNA were cultured in a $6 \mathrm{~mm}$ culture plate. The supernatant was removed for cortisol level detection. Standard solutions were diluted into different concentrations $\left(0,1,3,10\right.$ and $\left.60 \mu \mathrm{g} \mathrm{dl}^{-1}\right)$, then $10 \mu \mathrm{l}$ of each standard solution and cell supernatant were each added into a 96-well plate in which each well contained glass beads coated with anti-cortisol IgG. An enzyme immunoassay assay and a UBIMAGIWEL cortisol QUANTITATIVE kit (United Biotech Inc., CA, USA) were used to detect and quantify the cortisol levels. One hundred millitres of cortisol enzyme conjugate solution was added into each well, mixed with the mixture, and then placed at room temperature $\left(22-27^{\circ} \mathrm{C}\right)$ for $60 \mathrm{~min}$. Next, the well was washed with distilled water five times, followed by the addition of solutions $\mathrm{A}$ and $\mathrm{B}$, and mixed thoroughly and incubated at room temperature for $30 \mathrm{~min}$. A $50 \mu \mathrm{l}$ stop solution $(1 \mathrm{~N}$ $\mathrm{H}_{2} \mathrm{SO}_{4}$ ) was then added to stop the reaction and the results were qualified using an ELISA processor II (Boehring, Germany) at $450 \mathrm{~nm}$. Finally, the cortisol levels were measured according to the standard curve in $\mu \mathrm{g}$ per $10^{6}$ cells.

\section{RESULTS}

The normal human adrenocortical cells transfected with pK568MRSV plasmid were induced with $2.5 \mathrm{mM}$ IPTG., and the active RasGTP form was precipitated by GST-RBD of Raf- 1 fusion protein and immunoblotted as described in Materials and Methods. The RasGTP levels were detected at $0,1,6,12,24,36$ and $48 \mathrm{~h}$ after IPTG induction (Figure 1). The results showed that RasGTP levels in cells transfected with pK586MRSV increased with induction time. The phosphorated c-Raf-land phosphorated MAPK levels increased significantly at 1, 6, 12, 24 and $36 \mathrm{~h}$ after IPTG induction. The results of this Western blot analysis also revealed that phosphorylation of c-Raf-1 and MAPK was significantly enhanced when RasGTP level increased (Figure 2). Thus the inducible mutant $\mathrm{K}$-ras expression plasmid transfected adrenocortical cells expressed the mutant RasGTP in a time-dependent manner after IPTG induction. Concurrently, the amount of phosphorylated c-Raf and phosphorylated MAPK increased.

Furthermore, the kinase activity of MEK (MAPK kinase) was measured using myelin basic protein (MBP) as a substrate and significantly increased at $6,12,24$ and $36 \mathrm{~h}$ after IPTG induction (Figure 3). With pretreatment of $10 \mathrm{mM}$ PD098059 for $45 \mathrm{~min}$, pK568MRSV transfected adrenocortical cells were then treated with $2.5 \mathrm{~mm}$ IPTG. The mixture solution was incubated for $36 \mathrm{~h}$ in the presence of PD098059 and $2.5 \mathrm{mM}$ IPTG. Then the MEK activity was obviously inhibited (Figure 3, lane $36^{*}$ ). Moreover, steroidogenesis study by Northern blot showed that the density of mRNA of p450scc, p $450 \mathrm{c}_{17}$ and $3 \beta \mathrm{HSD}$ at each period was increased with time, but was also inhibited by PD098059 as shown in Figure 4A. Thus, inhibition of MEK/MAPK pathway also inhibited these enzymes' synthesis. Consequently, the cortisol production was increased significantly at $1,6,12$ and $24 \mathrm{~h}$, and the increase of cortisol production was also significantly blocked by PD098059 at $36 \mathrm{~h}$ after IPTG induction (Figure 4). By using PD098059, the MEK specific inhibitor, we could confirm that mutant K-ras gene

IPTG induction. And the elevated level of cortisol was blocked shown in (B) the 36* column. (B) *The 36* lane represented the pK568MRSV transfected cells treated with $10 \mu \mathrm{M}$ PD098059 for 45 min before the addition of $2.5 \mathrm{mM}$ IPTG and then incubation for $36 \mathrm{~h}$ in the presence of PD098059 and IPTG. Plus (+) indicates when present; minus $(-)$ indicates when absent. 
enhanced cortisol secretion in normal human adrenocortical cells through the Raf-MEK-MAPK pathway.

\section{DISCUSSION}

The present study showed that the adrenocortical cells transfected with $p K 568 M R S V$, an inducible mutant K-ras expression plasmid, expressed the mutant Ras protein in a time-dependent manner after IPTG induction. At the same time, the amount of phosphorylated c-Raf and phosphorylated MAPK were also increased. To clarify whether mutant K-ras gene regulated cortisol levels by MEK/MAPK pathway, we used PD098059, a specific MEK inhibitor (Alessi et al, 1995; Dudley et al, 1995), to block the signal transdution of the active RasGTP after IPTG induction. PD098059 is a synthetic inhibitor of the Ras-MAPK pathway that specifically blocks the activation of MEK. PD098059 has subsequently been used as a tool to study MAPK signalling in various cell types and in carcinogenesis (Reuter et al, 2000, blood). The inhibition of MEK activation was demonstrated to prevent activation of MAPKs (ERK-1/2) and subsequent phosphorylation of MAPK substrates both in vitro and in intact cells (Alessi et al, 1995; Dudley et al, 1995).

In this study, the addition of PD098059 led to the reduction of the accumulation of P450scc, P450 $\mathrm{c}_{17}$ and 3HSD mRNA after IPTG-induction in transfected human adrenocortical cells by inhibited Ras-MAPK pathway. PD098059 also reversed the increased cortisol level in $p K 568 M R S V$ transfected human adrenocortical cells. In our previous study (Wu et al, 2002), we have proved that lovastatin, a pharmacological inhibitor of $\mathrm{p} 21^{\text {ras }}$ function (Roskelley and Auersperg, 1995), also reversed the increased cortisol level in mutant K-ras stably transfected human adrenocortical cells. Taken together, these proved that the mutant K-ras gene enhanced not only cell proliferation but also steroidogenesis in steroidogenic phenotype cells by activating of Raf-MEK-MAPK signal transduction pathway.

Previous research on regulation of steroidogenesis mostly focused on regulation of elevated hormone secretion caused by ACTH and Angiotensin II (Toaff et al, 1979; Roskelley and Auersperg, 1995). Little is known concerning the association of oncogene with steroidogenesis regulation. Our study found that the activation of genes encoding enzymes related to steroidogenesis were regulated by activating cyclic Adenosine $3^{\prime}, 5^{\prime}$ monophosphate (cAMP) regulatory protein to interact with specific sequences while cAMP was used as secondary messenger. These cAMP regulatory proteins included cAMP regulatory element-binding protein (CREB), Steroidogenic factor (SF-1) and sp1 (Morohashi et al, 1992; Waterman et al, 1992; Omura and Morohashi, 1995). Cytochrome P450scc(CYP11A1) removes the side chain of cholesterol after cholesterol has been transferred into cells by steroidogenic acute regulatory protein (StAP). It is, therefore, also an important rate-limiting enzyme of steroidogenesis process in adrenocortical cells (Miller, 1988). Cholesterol was then used as substrate to produce different kinds of hormones via the action of $3 \beta \mathrm{HSD}$, $\mathrm{P}_{450 \mathrm{c}_{21}}$ (CYP21B), P450 ${ }_{17 \mathrm{a}}$ (CYP17) and P450 ${ }_{11 \mathrm{~b}}(\mathrm{CYP} 11 \mathrm{~B} 1)$. $\mathrm{P} 450$ regulatory enzymes were mainly regulated by cis-acting elements on promoter region including cAMP-responsive sequences (CRS), Ad4 and GC-rich sequences binding with corresponding proteins (Morohashi et al, 1992; Begeot et al, 1993; Guo et al, 1994; Tsukiyama et al, 1994; Omura and Morohashi, 1995). Meanwhile, steroid $17 \alpha$-hydroxylase and $3 \beta$-dehydrogenase can be regulated by cyclic AMP and protein kinase $\mathrm{C}$ secondary messenger system (Lund et al, 1997). Among all the positive gene regulations in hormone production, CREB, a highly expressive transcription factor in adrenal cortex, regulated steroid production by binding with frequently present CREB binding site in the promoter region of genes which encoding steroidogenic enzymes (Tsukiyama et al, 1994; Chung et al, 1997).

In many studies, the K-ras gene has been proven to take part in cell growth regulation by activating MAP kinase to activate transcription factor ELK-1 (Marais et al, 1993; Miranti et al, 1995). In 1996, Xing et al found that introduction of activated ras oncogene into PC12 cells regulated gene expression by activating RAF and MAP kinase and then RSK2 of pp90RSK family to phosphorylate CREB (Xing et al, 1996; Cesare et al, 1998; Beaupre et al, 1999). The CREB was the earliest found to regulate gene expression when the level of cAMP increases (Bonni et al, 1995). It also participates in the regulation of the cell response after the binding of growth factors with receptors (Bohm et al, 1995). Furthermore, CREB is a transcription factor for genes corresponding to steroidogenesis related enzymes (Watanabe et al, 1994; Kagawa et al, 1999). In this study, our laboratory proved that the mutant Ras protein enhanced not only the cell proliferation but also the steroidogenesis in steroidogenic phenotype cells by activation of Raf-MEK-MAPK signal transduction pathway. Therefore, in the future, we will use the cDNA microarray and other tools to examine the difference between the control cell and the K-ras transfected cell to understand the cross talks between the Ras-to-MAPK pathway and the regulation of the steroidogenesis process.

\section{ACKNOWLEDGEMENTS}

This study was supported by a fund from the National Science Council of the R.O.C. (NSC-88-2314-B-037-049).

\section{REFERENCES}

Alessi DR, Cuenda A, Cohen P, Dudley DT, Saltiel AD (1995) PD098059 is a specific inhibitor of the activation of mitogen-activated protein kinase kinase in vitro and in vivo. J Biol Chem 270: 27489-27494

Beaupre DM, Talpaz M, Marini IIIFC (1999) Autocrine interleukine-1B production in leukemia: evidence for the involvement of mutated RAS. Cancer Res 59: 2971-2980

Begeot M, Shetty U, Kilgore M, Waterman M, Simpson E (1993) Regulation of expression of the CYP11A (P450scc) gene in bovine ovarian luteal cell by forskolin and phorbol esters. J Biol Chem 268: 17317-17325

Bohm M, Moellmann G, Cheng E, Alvarez-Franco M, Wagner S, SassoneCorsi P, Halaban R (1995) Identification of p90RSK as the probable CREB-Ser133 kinase in human melanocytes. Cell Growth Differ 6: $291-$ 302

Bonni A, Ginty DD, Dudek H, Greenberg ME (1995) Serine 133-phosphorylated CREB induces transcription via a cooperative mechanism that may confer specificity to neurotrophin signals. Mol Cell Neurosci 6: $168-183$
Cesare DD, Jacquot S, Hanauer A, Sassone-Corse P (1998) Rsk-2 activity is necessary for epidermal growth factor-induced phosphorylation of CREB protein and transcription of c-fos gene. Proc Natl Acad Sci USA 95: $12202-12207$

Chung BC, Guo IC, Chou SJ (1997) Transcriptional regulation of the CYP11A1 and ferredoxin genes. Steroids 62: 37-42

Dudley DT, Pang L, Decker SJ, Bridges AJ, Saltiel AR (1995) A synthetic inhibitor of the mitogen-activated protein kinase cascade. Proc Natl Acad Sci USA 92: $7686-7689$

Elion EA (1998) Routing MAP kinase cascades. Science 281: 1625-1626

Fanger GR, Gerwins P, Widmann C, Jarpe MB, Johnson GL (1997) MEKKS, GCKS, MLKS, PAKS, TAKS, and Tpls: upstream regulators of the c-Jun amino-terminal kinases? Curr Opin Genet Dev 7: 67-74

Fredlund P, Saltman S, Catt KJ (1975) Aldosterone production by isolated adrenal glomerulosa cells: stimulation by physiological concentrations of angiotensin II. Endocrinology 97: 1577-1586 
Garrington TP, Johnson GL (1999) Organization and regulation of miltogenactivated protein kinase signaling pathways. Curr Opin Cell Biol 11: $211-$ 218

Guan KL, Dixon JE (1991) Eukaryotic proteins expressed in Escherichia coli: an improved thrombin cleavage and purification procedure of fusion proteins with glutathione S-transferase. Anal Biochem 192: $262-267$

Guo IC, Tsai HM, Chung BC (1994) Actions of tw sequences and an enhancer of the human CYP11A1 (P450scc) gene in adrenal Y1 and placental JEG-3 cells. J Biol Chem 269: 6362-6369

Herrmann C, Martin GA, Wittinghofer A (1995) Quantitative analysis of the complex between $\mathrm{p} 21^{\text {ras }}$ and the Ras-binding domain of the human Raf-1 protein kinase. J Biol Chem 270: $2901-2905$

Kagawa N, Bischof LJ, Cheng PY, Anwar A, Waterman MR (1999) Biochemical diversity of peptide-hormone-dependent regulation of steroidogenic P450s. Drug Metab Rev 31: $333-342$

Lin SR, Hsu CH, Tsai JH, Wang JY, Hsieh TJ, Wu CH (2000) Decreased GTPase activity of K-ras mutants deriving from adrenocortical tumors. Br J Cancer 82: 1035-1040

Lin SR, Tsai JH, Yang YC, Lee SC (1998a) Mutations of K-ras oncogene in human adrenal tumors in Taiwan. Br J Cancer 77: 1060-1065

Lin SR, Yang YC, Tsai JH, Hsu CH (1998b) Alteration of RET oncogene in human adrenal tumors. Jpn J Cancer Res 89: 634-640

Lin SR, Yang YC, Chang CH, Tsai JH (1996) A significant decrease on the transcriptional activity of p53 mutants deriving from human functional adrenal tumors. DNA Cell Biol 15: $793-803$

Lin SR, Lee YJ, Tsai JH (1994) Mutations of p53 gene in human functional adrenal neoplasms. J Clin Endocrinol Metab 78: 483-491

Lund J, Bakke M, Mellgren G, Morohashi K, Doskeland SO (1997) Transcriptional regulation of the bovine CYP17 gene by cAMP. Steroids 62: 43-45

Marais R, Wynne J, Treisman R (1993) The SRF accessory protein Elk-1 contains a growth factor-regulated transcriptional activation domain. Cell 73: $381-393$

Miller WL (1988) Molecular biology of steroid hormone synthesis. Endoc Rev 9: $295-318$

Miranti CK, Ginty DD, Huang G, Chatila T, Greenberg ME (1995) Calcium activates serum response factor-dependent transcription by a Ras- and Elk1 -independent mechanism that involves a $\mathrm{Ca} 2+/$ calmodulin-dependent kinase. Mol Cell Biol 15: 3672-3684

Morohashi K, Honda S, Inomata Y, Omura T (1992) A common trans-acting factor, Ad4-binding protein, to the promoters of steroidogenic P450s. J Biol Chem 267: $913-917$
Omura T, Morohashi K (1995) Gene regulation of steroidogenesis. J Steroid Biochem Mol Biol 53: 19-25

Reuter CW, Morgan MA, Bergmann L (2000) Targeting the Ras signaling pathway: a rational, mechanism-based treatment for hematologic malignancies? Blood 96: 1655-1669

Robinson MJ, Cobb MH (1997) Mitogen-activated protein kinase pathways. Curr Opin Cell Biol 9: 180-186

Roskelley CD, Auersperg N (1995) Rapid ras-oncogene-mediated transformation maintains steroidogenic differentiation in adrenocortical parenchymal cells. Differentiation 59: 103-111

Shu CH, Yang YC, Lian ST, Lee SC, Shin SJ, Lin SR (2001) Significant increased cortisol secretion in normal adrenocortical cells transfected with K-ras mutants deriving from human functional adrenocortical tumors. DNA and Cell Biol 20: $231-238$

Toaff ME, Strauss III JF, Flickinger GL, Shattil SJ (1979) Relationship of cholesterol supply to luteal mitochondrial steroid synthesis. J Biol Chem 254: $3977-3982$

Treisman R (1996) Regulation of transcription by MAP kinase cascades. Curr Opin Cell Biol 8: 205-215

Tsukiyama T, Niwa O, Hara T, Takakusu A, Shibata Y, Omura T (1994) Functional difference between Ad4BP and ELP, and their distributions in steroidogenic tissues. Mol Endocr 8: 643-653

Watanabe N, Inoue H, Fujii-Kuriyama Y (1994) Regulatory mechanisms of cAMP-dependent and and cell-specific expression of human steroidogenic cytochrome P450scc (CYP11A1) gene. Eur J Biochem 222: 825-834

Waterman M, Kagawa N, Zanger UM, Momoi K, Lund J, Simpson ER (1992) Comparison of cAMP-responsive DNA sequences and their binding protein associated with expression of the bovine CYP17 and CYP11A and human CYP21B genes. J Steroid Biochem Mol Biol 43: 931-935

Wu CH, Lee SC, Chiu HH, Yang CH, Lian ST, Shin SJ, Lin SR (2002) Morphological change and elevation of cortisol secretion in cultured human normal adrenocortical cells caused by mutant $\mathrm{p} 21^{\mathrm{K} \text {-ras }}$ protein. DNA Cell Biol 21: 21-29

Xing J, Ginty DD, Greenberg ME (1996) Coupling of the RAS-MAPK pathway to gene activation by RSK2, a growth factor-regulated CREB kinase. Science 273: $959-963$ 